\title{
Angiosarcoma of the Scalp: A Case Report
}

Bekralas H. ${ }^{1 *}$, Habchi N. ${ }^{2}$

${ }^{1}$ Head of Department of Neurosurgery Bejaia Hospital, Bejaia, Algeria

${ }^{2}$ Neurosurgery Department, Mustapha Pacha University Hospital, Algiers, Algeria

*Corresponding Author: Bekralas H., Head of Department of Neurosurgery Bejaia Hospital,Bejaia, Algeria

Received date: December 10, 2021; Accepted date: December 30, 2021; Published date: January 03,2022

Citation: Bekralas H., Habchi N. (2022). Angiosarcoma of The Scalp: A Case Report. J. Neuroscience and Neurological Surgery. 11(2); DOI: $10.31579 / 2578-8868 / 227$

Copyrights: () 2022 Bekralas H, This is an open-access article distributed under the terms of The Creative Commons Attribution License, which permits unrestricted use, distribution, and reproduction in any medium, provided the original author and source are credited

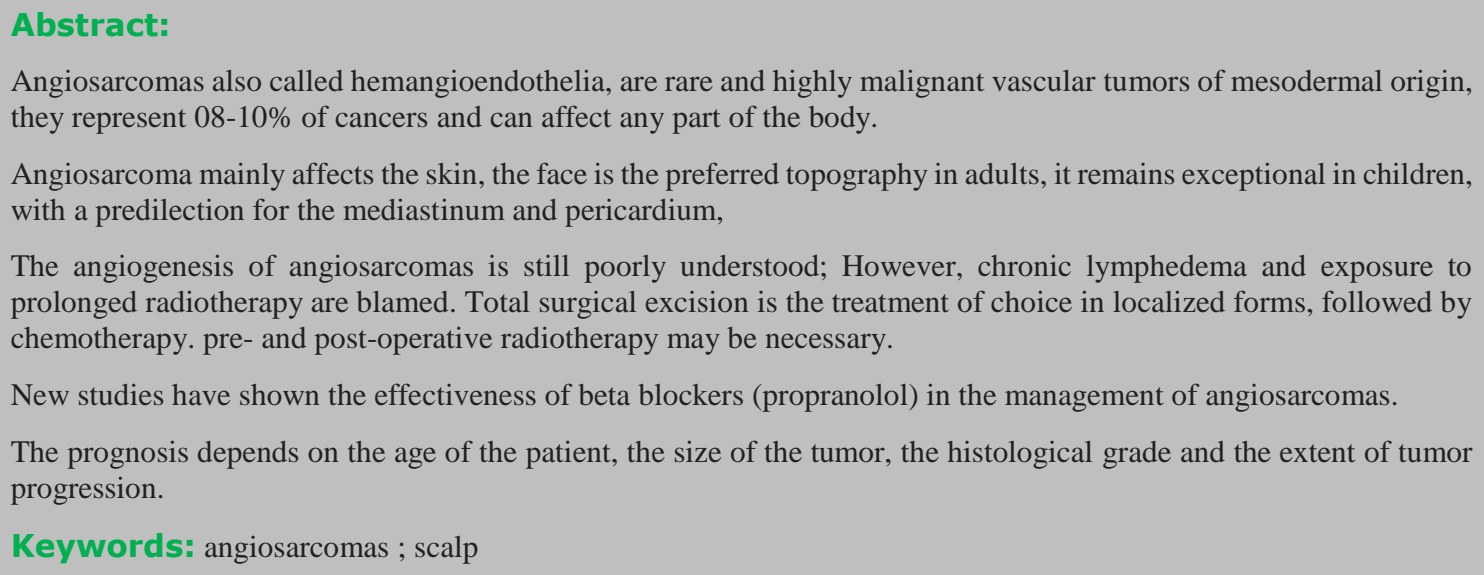

\section{Introduction:}

Cutaneous angiosarcomas are rare, aggressive vascular tumors with a poor prognosis; they represent approximately 1 to $5 \%$ of soft tissue sarcomas in adults and 0.2 to 0.3 in children.

WILSON - JONES angiosarcoma of the head and neck is a peculiar and exceptional topographic form in children. Congenital or intrauterine forms have been described in the literature.

\section{Materials and methods:}

We report a rare case of congenital angiosarcoma of the scalp in a newborn 7 days old, referred to our level by his pediatrician following the observation of an occipital lesion which rapidly increases in size.

The clinical examination found a conscious newborn, general condition preserved with skin-mucous paleness, in relation to anemia at $7 \mathrm{~g} / \mathrm{dl}$. Clinical examination finds a large, coarsely rounded mass, well skinned, hard, purplish, hyper vascularized and extended on the occipital surface, of progressive appearance. (Figure 01) 


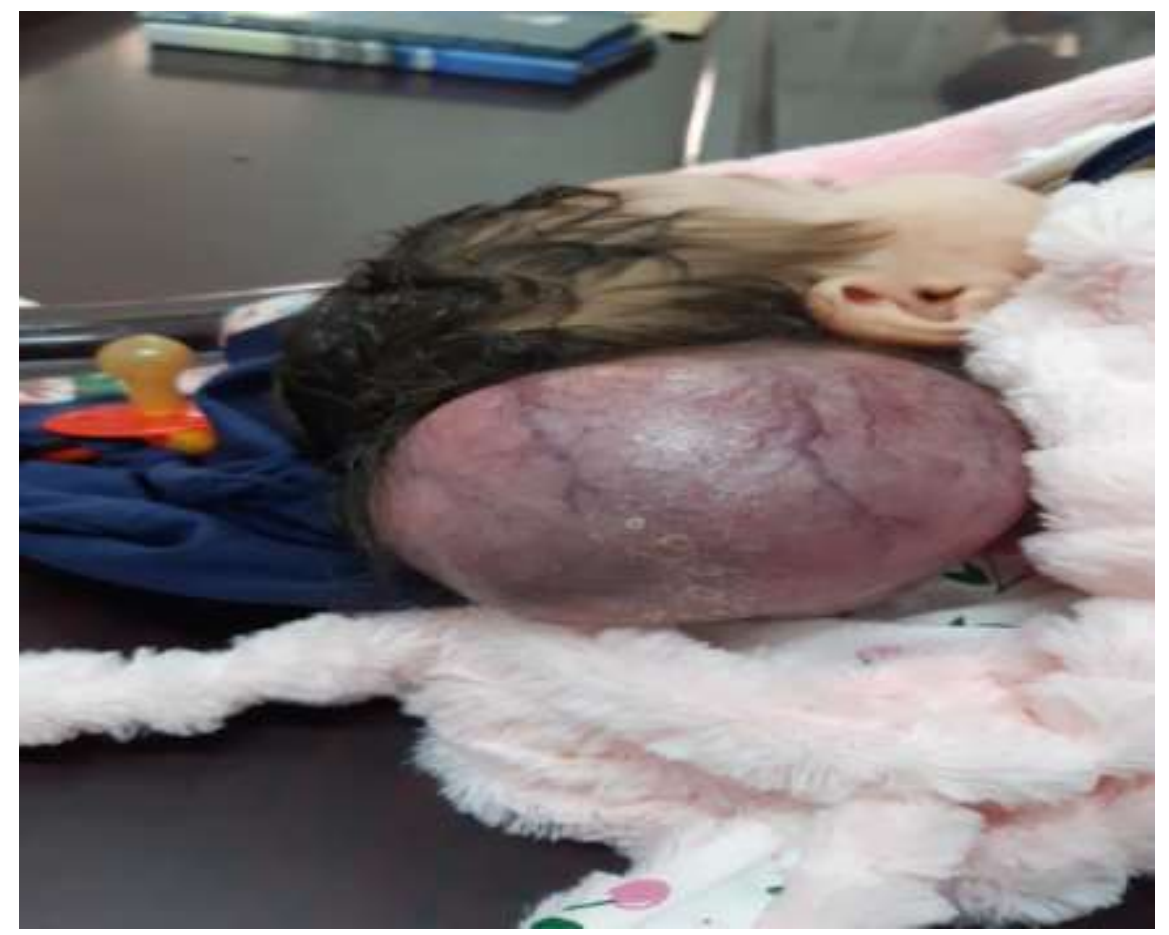

Figure 1 : The neurological and physical examination is unremarkable.

Cerebral computed tomography and brain angiography revealed a subcutaneous occipital lesion measuring $55 * 63 \mathrm{~mm}$ richly vascularized supplied by the branches of the occipital artery with infiltration of the galea and the external table. (Figure 02)

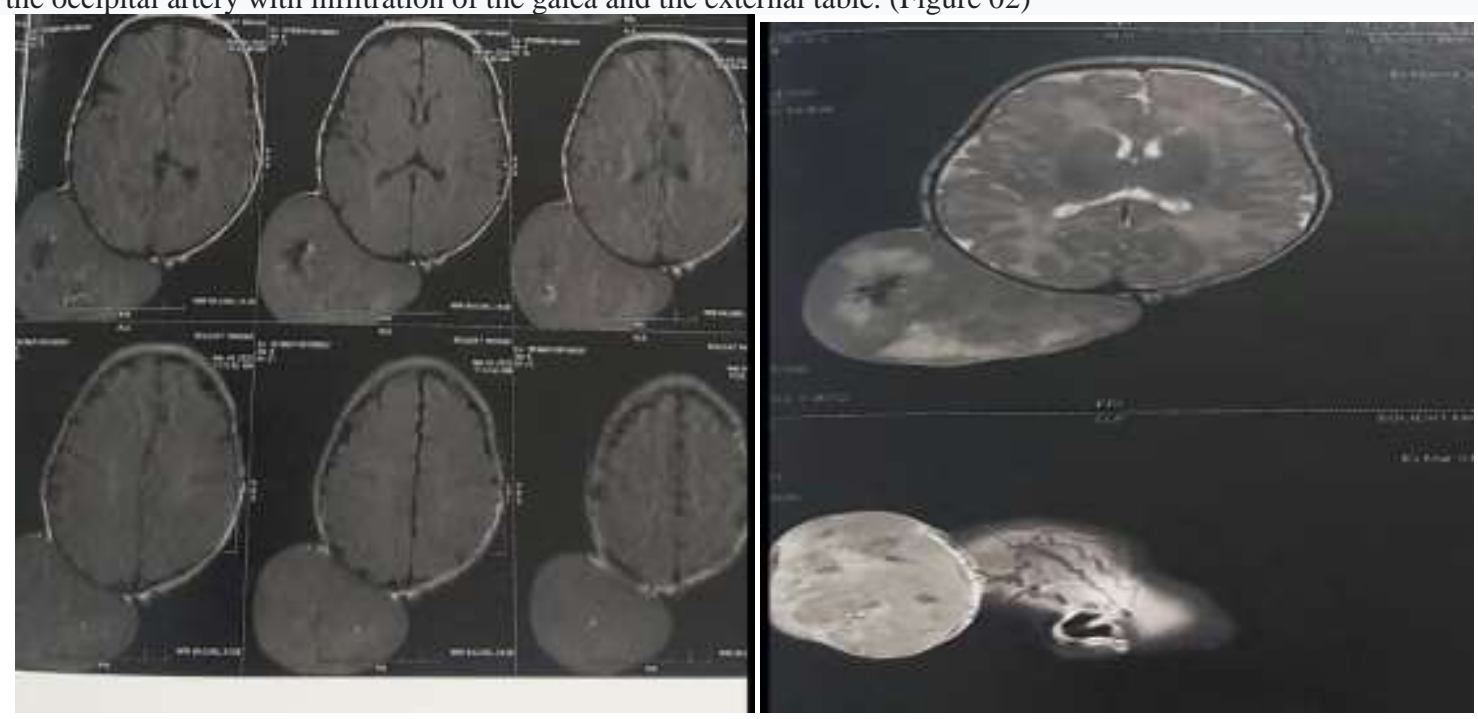

Figure 2 : After multidisciplinary consultation between neurosurgeons, pediatricians and pediatric oncologists, treatment with a propanolol-type beta-blocker was started for one month, followed by total surgical excision, with good postoperative treatment.

The pathological examination concludes with angiosarcoma, an orientation in oncology for an adapted chemotherapy made. (Figure 03) 

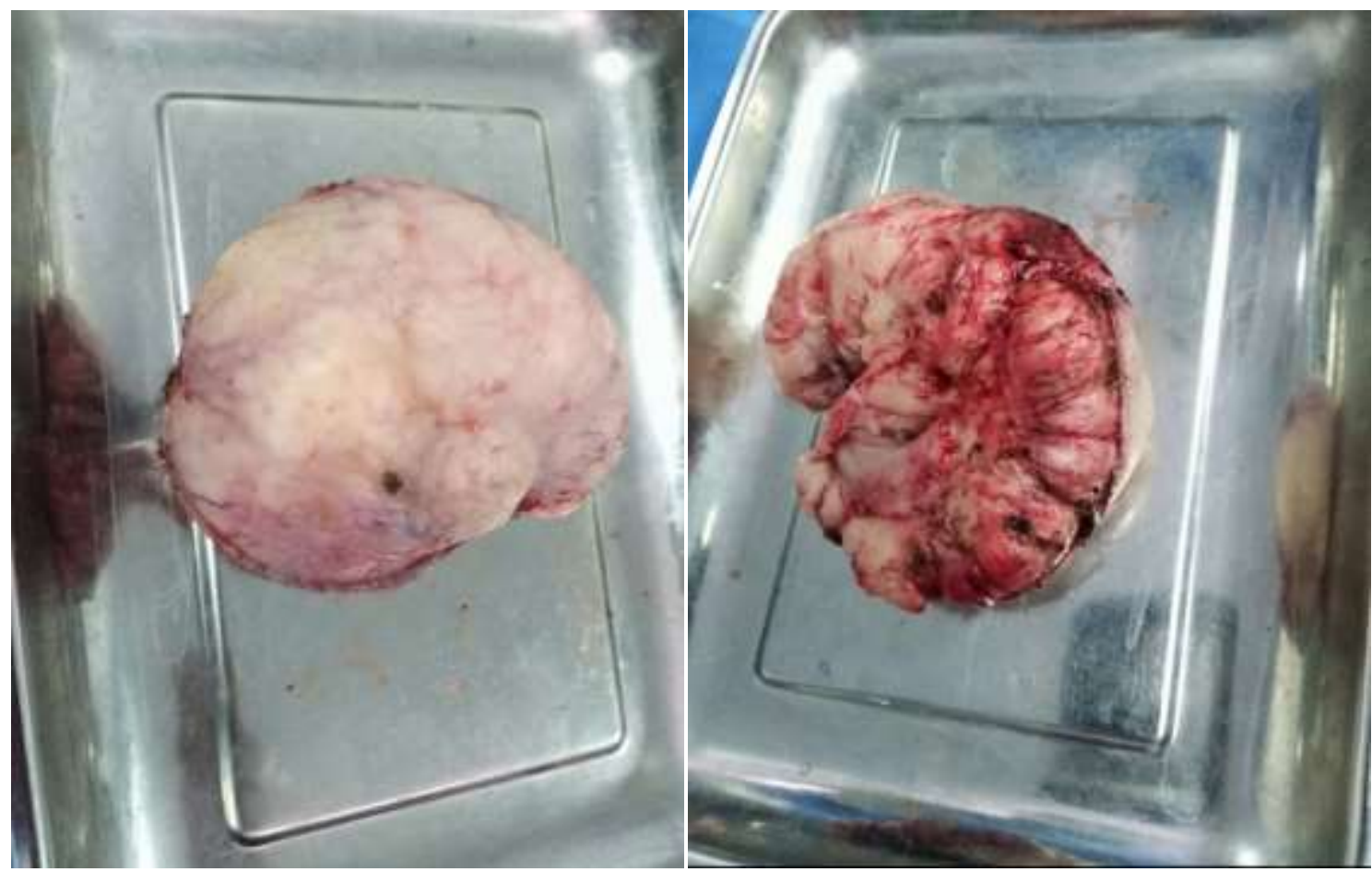

Figure 3: Operative part

The course at 1 year postoperatively is favorable, no signs of local or metastatic recurrence.

\section{Conclusion:}

Angiosarcomas are highly malignant tumors, the cutaneous form mainly affects the elderly, it is exceptional in children.

The antenatal diagnosis confirms the congenital nature of our elucidated case.

The rarity of congenital forms makes it difficult to institute an adequate therapeutic protocol.

The definitive diagnosis of angiosarcoma is histological.

The management is multidisciplinary: surgical treatment is the treatment of choice, it is generally followed by adjuvant treatment based on chemotherapy and radiotherapy.

Despite advances in neuro-oncology, the prognosis remains bleak.

\section{References}

1. Google sholar

2. http://emedicine.medscape.com/article/276512-clinical

3. https://www.rarecancers.org.au/directory/237/angiosarcoma

4. http://sarcomahelp.org/angiosarcoma.html\#tpm1_2

5. https://sarcoma.org.uk/sarcoma-types/angiosarcoma

6. www.mayoclinic.org/.../dxc-20323073

7. https://www.ncbi.nlm.nih.gov/pubmed/20537949

8. http://www.knowcancer.com/oncology/angiosarcoma/

9. http://sarcomahelp.org/angiosarcoma.html\#tpm1_2

10. http://emedicine.medscape.com/article/276512-overview

11. http://www.knowcancer.com/oncology/angiosarcoma/angiosarco ma-symptoms-types/

12. https://www.rarecancers.org.au/directory/237/angiosarcoma

13. https://sarcoma.org.uk/sarcoma-types/angiosarcoma

14. http://www.archivesofpathology.org/doi/full/10.1043/1543-2165134.3.481 ?code=coap-site

15. https://www.ncbi.nlm.nih.gov/pmc/articles/PMC3907509/

16. https://www.bcrt.org.uk/information/information-bytype/angiosarcoma/ 
(c) (7)

This work is licensed under Creative

Commons Attribution 4.0 License

To Submit Your Article Click Here: $\quad$ Submit Manuscript

DOI: $10.31579 / 2578-8868 / 227$
Ready to submit your research? Choose Auctores and benefit from:

> fast, convenient online submission

$>$ rigorous peer review by experienced research in your field

$>$ rapid publication on acceptance

$>$ authors retain copyrights

$>$ unique DOI for all articles

$>$ immediate, unrestricted online access

At Auctores, research is always in progress.

Learn more https://auctoresonline.org/journals/neuroscience-and-neurologicalsurgery 